\title{
Intersections of Humanities and Engineering: Experiments in Engineering Specific Humanities Electives and Pedagogies
}

Mr. Alan Chong, University of Toronto

Alan Chong is a Senior Lecturer with the Engineering Communication Program at the Univ. of Toronto, and is the communication coordinator for Civil Engineering, where he teaches a second year communication course, and administers a third year civil engineering portfolio.

\section{Ms. Lydia Wilkinson, University of Toronto}

Lydia Wilkinson is a lecturer in the Engineering Communication Program at the University of Toronto. She holds a Bachelor of Education and a Master's in Drama. She has published articles on performance and on communication, and has edited journals and anthologies

\section{Ms. Deborah Tihanyi, University of Toronto}

Deborah Tihanyi is a Senior Lecturer in the Engineering Communication Program at the University of Toronto. 


\section{Intersections of Humanities and Engineering: Experiments in Engineering Specific Humanities Electives and Pedagogies}

\section{Introduction:}

A significant amount of research, reflected in the 2000 ABET requirements, has acknowledged the importance of a broad-based, liberal education for engineering students' critical reading and thinking abilities. Yet the question of how to integrate that education into already bursting engineering curricula remains a challenge. For engineering students, many of whom still define themselves in opposition to the "artsies" residing on the other side of campus, the opportunity to take a humanities elective in another program is often fraught with anxieties about academic expectations, unfamiliar pedagogical approaches, and engineering vs. arts student stereotypes. In some universities, engineering students are also given lower priority in registering for humanities courses, making selection of desired subjects and courses even more challenging.

At the University of Toronto, the Faculty of Applied Science and Engineering has taken an alternative approach to these challenges by developing in-house humanities and social science electives designed specifically to appeal to engineering students. The courses operate at the intersections between humanities and engineering, and are staffed by faculty members from the Engineering Communication Program (ECP). Although the ECP's main responsibility is to teach communication skills to engineering students, their faculty's diverse backgrounds in theatre, literature, and education, alongside their understanding of engineering student needs make them well suited for these electives. Teaching humanities activities and pedagogies while focusing on comparatively familiar topics in science and engineering encourages students to engage more confidently in an unfamiliar discipline.

Several different courses, focusing on different intersections, now exist. "Representing Science on Stage" focuses on the intersections between science and theatre, framed by an attempt to define "science/scientist" and "performance/performer," and to pull apart stereotypical binary pairs--rational vs. imaginative, objective vs. subjective, intellectual vs. emotional--using plays with science as its subject matter. Another course, "Representing Science and Technology in the Popular Media" teaches literary and critical analysis through close examination of popular science texts, particularly science journalism. It takes advantage of the students' scientific backgrounds, which affords them a deeper ability to assess the validity, identify characteristics, and critique the techniques employed in the prose.

This paper describes the motivation behind developing humanities electives that exist at the intersection of the humanities and engineering, and examines instructor experiences and student feedback from the courses to reach several important conclusions. First, the classroom atmosphere created by a group of engineering students participating in traditionally humanities pedagogies, in which their disciplinary expertise brings to bear some important perspectives on 
the content, is unique and highly valuable. Second, students see the relevance of their experience in these courses to their chosen careers more clearly. And finally, these intersections begin to break down traditional binaries between engineering and the arts within an instructional environment that takes for granted their ability to contribute meaningfully to a discourse that is separate but complimentary to their own.

\section{Background:}

Arguments for a liberal education for engineers identify a number of positive outcomes stemming from required courses in the Humanities and Social Sciences: through immersion in the liberal arts students become more culturally aware, are capable of inter- and crossdisciplinary collaboration, have stronger communication skills, and are capable of learning outside of their discipline even after leaving the academic environment ${ }^{1-7}$. As Duderstadt argues in his response to the Engineer of 2020, each of these positive outcomes helps to produce engineers who are better equipped for a changing professional environment, in which the ability to quickly master and respond to new technologies in collaborative often global work environments may be more important than the basic engineering skills taught within the current undergraduate curriculum ${ }^{2}$.

While the benefits of a liberal education may be clear, the practicality of providing these opportunities while competing with the time constraints of the core curriculum is a challenge. Canada's accreditation criteria stipulates a minimum of 225 academic units (one AU is equivalent to one 50 minute lecture period or a 30 minute lab) shared between all complementary studies. Our accreditation board acknowledges the need for interpretation and judgement while distributing these units across the range of topics covered by this category, noting:

While considerable latitude is provided in the choice of suitable content for the complementary studies component of the curriculum, some areas of study are essential in the education of an engineer. Accordingly, the curriculum must include studies in the following:
a. Engineering economics
b. The impact of technology on society
c. Subject matter that deals with central issues, methodologies, and thought processes of the humanities and social sciences
d. Oral and written communications
e. Health and safety
f. Professional ethics, equity and law
g. Sustainable development ${ }^{8}$ 
Across the Faculty, the allotment of Humanities and Social Sciences (HSS) electives fulfilling the complementary studies requirement ranges by department from two to four half credit courses.

Our faculty's engineering calendar provides a fairly restrained argument for the benefits of immersion in the liberal arts, explaining that: 'Engineers' colleagues frequently have a background in the humanities and social sciences rather than in the physical or mathematical sciences, so students need to have some understanding of the modes of thought used in these disciplines" 9 . The fact that this argument takes for granted a fundamental difference between engineers and all other disciplines, as well as the possibility and sufficiency of developing an understanding of the way that modes of thought are used without actually applying them, is not surprising in that it mirrors our students' experiences. Differences between complementary studies offered from within the engineering faculty in topics like engineering ethics and economics, and those outside the faculty in typical humanities courses are frequently noted by students. They report a lack of familiarity with the pedagogical approaches and classroom structure in their HSS lectures and tutorials. If they manage to enroll in a course with comparatively low engineering representation, they often feel isolated from their peers, and if they choose to enroll in an HSS elective with high out of department enrollment they are often shepherded into a non-arts and science lecture section or tutorial with no change in the way that material is delivered or discussed. While they may watch different modes of thought at work, it's unlikely that they are proficient in their use or convinced of their benefit by course's end. And while another calendar entry strongly encourages students to "plan their complementary studies electives in accordance with their career aspirations" ${ }^{9}$, the limited spots for these outsiders restricts their choice of elective. While these conditions seem to support the type of anthropological experiment suggested by our calendar description, they work in counterpoint to the environment of collaborative learning, cross-disciplinary knowledge-sharing and confidence building that will help to produce competitive future engineers.

The elective courses developed by ECP respond to these challenges by introducing engineering students to a liberal arts pedagogy and approach, while covering content that is immediately relevant to their future career and academic interests. The structure of these courses, which rely on class-directed learning and discussion, helps students to develop the ability for lifelong learning outside of their discipline that is so central to the argument for increased liberal arts integration.

\section{Representing Science on Stage:}

Representing Science on Stage challenges engineering students to engage with science through culture, specifically theatrical performance. In two-hour weekly seminars, students explore the science, social/historical context and stagecraft in three published play texts; the plays change from year to year but are always about science or scientists (past plays have included Bertolt 
Brecht's Galileo, Carl Djerassi's Oxygen [this play actually written by a scientist], Michael Frayn's Copenhagen, Maureen Hunter's Transit of Venus, Wendy Lill's Chimera, John Mighton's The Little Years, Vern Thiessen's Einstein's Gift). In two-hour weekly studio classes, students receive instruction in acting and directing and create three scene performances.

The key objectives for the course are to have students:

1. Analyze how science is mediated through/by culture, specifically the performing arts and more generally through the relationship between science and the humanities;

2. Develop basic performance skills through improvisation and scene study;

3. Build on written and oral communication skills; and

4. Add breadth to cultural knowledge.

While theatre provides the frame for the course, these objectives aim to provide students with transferable skills and a venue through which they can explore and express different sides of themselves.

We always begin the course with an exercise in comparing notions of "performance/performer" and "science/scientist." Students are divided into groups of five or six and given large sheets of paper and markers; in their groups, they brainstorm around the notions and record their thoughts (including words and drawings). After each group has completed their poster, they rotate to the next group's poster, adding their own commentary. Once each group has rotated through all posters, they return to their own for a final look. The class then regroups as a whole to discuss what has been discovered.

What repeatedly emerges from this exercise is, at first, what we might expect: the traditional binary opposition between "performance/performer" and "science/scientist." Performers are emotional, intuitive and social while scientists are intellectual, analytical and "loners." However, as students discuss the ideas among themselves and explore those of their classmates, they begin to articulate commonalities: the presence of unique "languages" in both performance (e.g., music) and science (e.g., mathematics); the importance of communication and critical thinking; the need for rehearsal or experimentation; the reliance on innovation and creativity. We often do the same exercise in the last seminar class of the term, and here the commonalities are further reinforced: the importance of design in both engineering and theatre; the necessity of teamwork; the need for iteration.

The seminar activities require students to draw on their knowledge of science to better understand the themes emerging from the plays, as well as to develop their ability to create coherent arguments to support their analysis. Two of the main seminar activities are the debate and the table read. In the debate, students are divided into teams and given a resolution related to a theme or issue studied in one or more of the plays; this provides a useful format for reviewing material from the previous play unit or the course as a whole. For example, one debate last semester focused on the differences between pure science and applied science, and asked teams 
to argue for or against the motion that "science with no immediate application has no value." The debaters had to review all three plays studied over the semester to develop arguments for or against this idea, and could build the strongest arguments while relating this issue back to their own experiences as applied scientists. Through this exercise, students were given an opportunity to define and reflect upon their field of study, while engaging more closely with the course texts.

In the table read, we select a few scenes from the play currently under consideration; students are assigned roles and read the text several times. Part of the purpose of the table read is to introduce students to how the rehearsal process begins. In professional practice, the table read is an opportunity for the actors to begin to explore their characters and for the designers and director to share their initial ideas. As such, it gives us a forum in which to discuss the responsibilities of each theatrical position, helping students to later choose their role for the final scene performance (one of actor, designer, director). The table read also serves the purpose to explore critical analysis and its application within theatrical practice: the need to make use of extratextual resources (e.g., historical research) to deepen the interpretation of the play; how individual words, lines and scenes contribute to the construction of character, theme and story; the ways in which these constructions can be portrayed vocally, physically, visually and aurally; the process through which actors, directors and designers facilitate each other's work, even in the early stages. Given the subject matter of the plays, students can draw on their own subject expertise in these discussions, but must also think beyond material covered in their core courses to knowledge acquired outside and before their undergraduate curriculum, for example recalling high school history lessons, or exercising their ability to understand and analyze interpersonal behaviours.

The studio classes are organized around the students' creation of their three scene performances. Studio classes generally consist of a warm-up, which includes vocal and physical exercises meant to build the students' theatrical instruments, and rehearsal time for the scene performance groups. Typically students work intensively in their small groups while receiving regular feedback from the instructors. Less frequently, the class participates in "live rehearsal" which brings the private rehearsal process to the whole class. For example, a team might perform part of their scene, after which they receive feedback-comments and questions-from the students and instructors. Students benefit from a larger audience as well as from the instructors' prompts; the instructors' experience in acting and directing, for example, allows them to model techniques for facilitating performance (techniques which the students will often take up in their own, private rehearsals). The exercise also gives students in the audience a chance to use their experience through the course to help one another: they now have the language and confidence to constructively critique their peers.

The course is very much about collaboration (between instructors, between students and between instructors and students) but, more than that, it benefits from the trust that forms quickly between people participating in theatre practice, as well as the sense of ownership of that practice. 
Students often comment that they have never been able to get to know their classmatesparticularly from other engineering disciplines-as intimately as they do in APS320. This kind of trust allows for the free expression of ideas, the negotiation of often controversial topics and the ability to experiment with new vocal and physical techniques. By necessity students must engage with subject matter from both inside and outside of their own engineering discipline and the sciences more broadly, and this type of synthesis anticipates the inter and cross-disciplinary work environments that they will encounter as engineers. Finally, because the students create the course material-both in seminar and studio-and, perhaps, because they often feel such a close intellectual and emotional connection to that material, they develop a deep sense of ownership of the work and an understanding of the value of actively shaping their learning experience.

\section{Representations of Science and Technology in the Popular Media:}

Representations of Science and Technology in the Popular Media engages a slightly different set of intersections between humanities and engineering. Its foundations are in the traditional principles of critical reading and literary analysis, though the analytical focus often stretches beyond literary texts, into film and multimedia. For engineering students, a majority of the reading done in their core technical courses does not demand critical analysis. When faced with an assigned reading in structures or thermodynamics, for example, the most efficient approach for students would be to find the quickest way to absorb the information for regurgitation on a test or, in a more ideal scenario, understand the information in order to apply it to a problem set. However, critical reading skills are an essential component of the analytical skills valued by engineering accreditation agencies-in their graduate attributes-and by employers. Furthermore, strong writing and presentation skills are honed by and rely on rhetorical strategies typically developed through a critical reading practice.

As mentioned previously, the course focuses its analysis on popular science texts, using case studies in science journalism. By using techniques of literary criticism on these texts, and studying the circumstances of their production, we take advantage of the students' scientific backgrounds. A basic, straightforward analysis would involve examining various newspaper stories or news coverage of a scientific finding, contrasted against the findings of the actual scientific paper yet also set against various press releases and backgrounders produced by the authors and institutions involved in the research. By examining the differences between the popular science representations and their original documents, students see the transformative process of science popularization, and begin to understand the factors and agents involved. Here, the engineering students' technical background affords them a deeper ability to assess the validity, identify characteristics, and critique the techniques employed in the prose. Their intrinsic interest in the subject, alongside the implications of public science communication to their careers, provides us an opportunity to engage traditional rhetorical concepts such as narrative and metaphor, alongside discipline specific issues, in a non-threatening and compelling environment. 
The course begins in a controversial claim about science commonly attributed to Einstein: "Most of the fundamental ideas of science are essentially simple, and may, as a rule, be expressed in a language comprehensible to everyone" ${ }^{10}$. Einstein's claim brings up a number of important questions. Popular media today is highly saturated with science and technology news so we might at first agree, but how that information is disseminated, by whom, and for what purpose remain important issues for science communication, and complicate the democratic notion of science espoused above. What is lost in the translation when disciplinary experts communicate their findings to a general audience? What happens when science journalists, rather than the scientists themselves, take on the responsibility for popularising science? What are the implications-for scientists and the public-when science is used to support a political, social, economic, or even moral agenda? The course addresses the relationship between science, scientists, and the public by examining representations of science and technology in the popular media, concentrating on popular science books and science journalism (in both traditional and new media, including documentaries, news reporting, and other science programming).

Focusing on questions of accuracy, accessibility, agency, and appropriation, the course first develops theoretical models for and explores methods of popular science communication, and then turns to popular science texts themselves, examining how fields of knowledge are constructed in the public sphere. The course's examination of accuracy addresses both the correctness of popular reporting on science, as well as the differences between scientific and journalistic understanding of accuracy. Questions of accessibility focus on the strategies for making science understandable to the general public, as well as the issue of access to scientific materials. Engaging the issue of agency requires a discussion of the role of scientists, journalists and editors in constructing the messages that reach the public, and is connected to the issue of appropriation, which engages how the public message of science is used for political, social and economic agendas. The four essential concepts are tied deeply into the course learning objectives, as stated in the course syllabus:

1. Differentiate between processes, goals, and methods for academic versus popular scientific publication

2. Understand the historical forces that have lead to current modes of popular scientific discourse and communicative practices

3. Explain how contrasting models for the popular communication of science can determine relationships between scientists, science, and the public

4. Understand how science journalists find, research, pitch, and frame stories to editors and audiences

5. Critically assess popular media representations of science and technology research, focusing on:

a. How journalistic values, techniques, and processes contribute to popular science knowledge and/or misconceptions 
b. How modes of representation, such as analogy, metaphor and narrative, commonly used in popular science writing both dilute and enrich scientific knowledge

c. How science is "framed" 11 to support various agendas, and how that appropriation affects the public's understanding of science

6. Understand how scientific controversies play out in the popular media, particularly in relation to the communication of risk

7. Understand the implications of popular media representations on not only the public understanding of science, but also how science and technology research is constructed, funded, and documented

8. Improve written and oral communication skills through complementary studies, including developing effective rhetorical techniques and strategies for communicating science to non-specialists

We spend the first eight weeks studying the history of popular science, methods and strategies for communicating science to the public, as well as established, theoretical models for understanding the relationship between scientists, science, and the public, mostly through case studies. Over the years, sample case studies that have helped to illustrate key concepts have included:

1. Sensationalism and apocalyptic rhetoric coverage of the Large Hadron Collider

2. North American media reporting on the Swine Flu epidemic

3. Ethics in the reporting of "breakthrough" medical research

4. The politics of framing climate change science, as seen through:

a. The inaccuracies of journalistic (im)balance

b. Reporting on natural disasters (such as Hurricane Sandy)

c. Reactions to A Silent Spring from publication to its 50th anniversary

5. The emergence of science by press conference (NASA's arsenic based life form findings) The immediacy of the events and texts discussed in the course make discussions lively and compelling for students. For example, reporting around the Swine Flu epidemic became an important part of the risk communication aspect of the course during its outbreak. Stories around the Large Hadron Collider played a large role in the course with its launch in 2008, took on a smaller role in the course after its launch, but became a larger concern again with the discovery of the Higg's Boson in 2012. NASA's highly critiqued and public announcement of arsenic based life forms in 2011 arrived in the middle of the course, and allowed discussion around the issues with science by press conference. The introduction of more current theoretical models, being shaped by current events, is essential in helping students to understand the implications of current scientific public debates-such as the discussion around climate change-as well as the representations of key scientific discoveries over the course of the term. In the last iteration of the course, attempts to keep the class topical and current led to some very fruitful and timely discussions around issues like Risk Communication in the face of Hurricane Sandy and the 
L'Aquila earthquake verdicts. Students commented positively on having the chance to contribute to class discussion on contemporary topics.

In the final five weeks of the course, the class is turned over to student seminars: students are responsible for a 50-minute seminar on a topic of their own choosing, in which they are asked to apply the theory taught in the first half of the course to develop a critique or analysis of one particularly important science story, a specific text, or method for disseminating science to the public. Memorable seminar topics have included:

1. The role of mythbusters in popularizing science

2. Raymond Kurzweil's Age of Singularity

3. Nutritional labelling and health sciences

4. The (lack of) science behind diet and exercise claims

5. The role of science centres in education and popularization

The student run seminars are a big part of the course's success and appeal to the engineering students, largely because they give students control over course content and allow them not only to explore their own interests, but also communicate them to their peers and engage in dialogue about them. In these seminars, the students demonstrate a critical understanding of the concepts discussed early in the term as well as the ability to apply them.

\section{Methods:}

Initial student feedback on the courses have been taken from course evaluations, which target general questions about the course quality and offer students an opportunity for free form response to the course itself. Additionally, responses to Science on Stage have been drawn from the course blog, which provides a space for unstructured course feedback.

This year we will survey current students and students from the past five years with questions specifically targeting the intersections of science and humanities to supplement the formal evaluation results and provide data specifically related to our hypothesis in this paper. The survey questions are outlined below:

1. How was your experience in this course similar to, or different from, humanities and social science electives you've taken in the past?

2. How did the environment of primarily engineering students in a relatively small class effect your experience in this course?

3. How did our application of non-traditional engineering approaches to scientific and engineering content determine your experience of the course?

4. How relevant were the approaches, materials, and overall experience to your engineering education?

5. How have you applied, or how will you apply the knowledge and experiences acquired through this course to your engineering practice? 


\section{Findings:}

Data from this survey is anticipated by the final version of the paper, but data from student evaluations already indicates a specific type of value ascribed to the courses by engineering students.

\subsection{Representing Science on Stage}

While Representing Science on Stage uses end of semester course evaluations to measure student response to the course, more extensive feedback is available through the course blog that runs all term. The entries often pick up on activities or discussion emerging from seminar and studio, but they also include spontaneous evaluations by the students. Some entries, like the following blog posts, illustrate the reconciliation of the "artsies"/engineering divide, as well as the importance of having a change of pace from typical engineering pedagogy-one that allows for freedom of expression:

- I really enjoy taking this course in a sense that it uses my other side of the brain (from all the math, equations, programming, etc).

- In reference to the book "Human Factors", it speaks about how people are either Science or Arts. And the bridge between the two people is difficult to connect. But what if one person could be both? Like John Mighton who is both a playwright and a math teacher. I feel that our science could become better if our scientists had a hobby that has nothing to do with science, and our art could become better if our artists had a hobby that has nothing to do with art. It's the contrast between the two that could make people better. Instead of just dividing people into two different categories, people should just intrinsically be both!

Others, like the following response, point to a number of key transferable skills-reading, analysis, argumentation, public speaking and brainstorming techniques-that students can now apply in their engineering and design courses:

- The course gave me the confidence to speak out my opinions, which is completely different from being comfortable with presenting. Presenting a topic that you know well is easy as it boils down to talking about facts; however, speaking about your opinions about a certain subject is much more difficult since you have to find a way to convey what you mean to your peers.

Finally, some posts bring these multiple threads together, to articulate both their emerging understanding of arts and science pedagogies as well as their usefulness in engineering practice: 
- I have always struggled in understanding the underlying messages in plays and short stories in particular. I always understood the words and what was happening in the play/short story (on the outside) but not necessarily the underlying message or the cues that the author is conveying. I also thought that only artscis can do that (embarrassed face, I am admitting that artscis could be better than us) because their education helped them in that. I remember hating that when I was younger because it made me feel less intelligent. [...] After taking this course, I may not have become a director or playwright, but I have definitely become a better reader and that I am grateful for that.

- Thinking back to when we all started writing our first scene performances, everyone was stuck sitting in their groups and trying to systematically plan out the script and staging in their heads rather than getting up and trying it. It's something that we aren't taught a lot of in engineering. I can't count how many times I've had a group report to write and we've sat there deliberating on how exactly we want to write it, when it would have been much easier to just start writing what ever comes to mind, and then editing later. I think that free "artistic" style of thinking (not saying that artists aren't systematic in what they do) is something we can all learn from.

\subsection{Representations of Science and Technology in the Popular Media}

For Representations of Science and Technology in the Popular Media, the comments come from the free form response section of the official course evaluations, a sample of which are provided below. Notable is that these responses indicate that many students consider the course an important aspect of an engineering education, helpful in particular with negotiating their relationship with the public and the "world outside" of engineering, as well as thinking about their own identities and roles as engineers.

- Looking at science with a critical eye "from the outside" and the effect of scientists on public opinion got me thinking a lot about my potential in the future as an engineer.

- Very good course - more of these types of courses should exist in the engineering faculty ... it got us thinking of the world around us, which engineers often do not. The seminars were a very positive experience.

- The course was very interesting. ... The course material is essential for individuals with a technical background to empower themselves to see eye-to-eye with non-technical representations of their own works.

Furthermore, they point towards students' understanding of the importance of critical reading and thinking within an engineering and science context:

- I think this was the best course in my university life as an engineer because it gives students freedom to express/analyze topics not completely in engineering, plus the experience of running seminars and writing essays was good. 
- Great course, especially for engineers, one of few opportunities for a class where you can participate in discourse, form and defend arguments, etc. Important skill, should be recommended for more engineers.

- This course is definitely needed by all engineers.

Our analysis remains in progress, and as stated above, data from the survey and the associated discussion will be forthcoming in the ASEE 2014 conference presentation. In particular, feedback from students several years removed from the course will be valuable in assessing longer term effects of the learning and environment created in these humanities and social science electives for engineers.

\section{Conclusion:}

While these courses may not offer a liberal arts immersion in the traditional sense (within a liberal arts classroom) they provide an alternative forum through which to develop those proficiencies promised by proponents of a liberal arts foundation for engineers, specifically an awareness of life outside the engineering classroom and science in its larger context; the ability to collaborate productively with colleagues outside one's discipline; strong communication skills; and an ability and interest in learning outside of one's primary discipline. The fact that these courses fail to break down the physical barriers between engineering students and their arts and science peers should not diminish their success in helping students not only to understand, but to successfully practice the unfamiliar 'modes of thought' that characterize a liberal arts classroom.

\section{Bibliography:}

[1] Kastenberg, William E., Gloria Hauser-Kastenberg, David Norris. "An Approach to Undergraduate Engineering Education for the 21st Century," American Society for Engineering Education Conference Proceedings, 2006.

[2] Duderstadt, James J. Engineering for a Changing World. A Roadmap to the Future of Engineering Practice, Research, and Education. The Millenium Project, University of Michigan, Ann Arbor, 2008.

[3] Akera, Atsushi. "Liberal Learning Revisited: A Historical Examination of the Underlying Reasons, Frustrations, and Continued Prospects for Engineering and Liberal Arts Integration," American Society for Engineering Education Conference Proceedings, 2011.

[4] Traver, Cherrice, J. Douglass Klein, Borjana Mikic, Atsushi Akera, Steven B. Shooter, Ari W. Epstein, David Gillette. "Fostering Innovation through the Integration of Engineering and Liberal Education," American Society for Engineering Education Conference Proceedings, 2011.

[5] Bordogna, Joseph, Eli Fromm, Edward W. Ernst. "Engineering Education: Innovation Through Integration," Journal of Engineering Education, vol. 82, no. 1, January 1993, pp. 3-8.

[6] Domenico Grasso, "Engineering a Liberal Education," PRISM, vol. 12, no. 2, November 2002, p. 76. 
[7] Lyman, Frederic A., "Opening Engineering Students' Minds to Ideas Beyond Technology," IEEE Technology and Society Magazine, vol. 21, no. 3, 2002, pp. 16-23.

[8] Engineers Canada. Canadian Engineering Accreditation Board Accreditation Criteria and Procedures, 2013.

[9] University of Toronto Faculty of Applied Science and Engineering. Academic Calendar, 2013-2014.

[10] A. Einstein and L. Infield. The Evolution of Physics, Simon and Schuster, New York, 1938.

[11] M. Nisbet and C. Mooney. "Framing Science," Science, vol. 316, no. 6 April 2007, p. 56. 